\title{
ENTRE O CENTRO E A PERIFERIA: O CENÁRIO RELIGIOSO EM SANTO ANTÔNIO DA PLATINA EM 2020
}

Between the center and the periphery: the religious scene in Santo Antônio da Platina in 2020

Alfredo Moreira da Silva ${ }^{1}$

Wesley dos Santos Araujo ${ }^{2}$

\section{RESUMO}

O presente artigo busca compreender como se configura o cenário religioso no município de Santo Antônio da Platina-PR. Este estudo de caso baseia-se na percepção de que diferentes movimentos religiosos se desenvolvem na região central e na periferia do município, portanto o principal objetivo deste trabalho está em diferenciá-los. A região central, como uma construção social e histórica, concentra não apenas pessoas mas também um capital simbólico importante para os templos que ali se localizam, além de estabelecer uma relação de proximidade com a administração pública. Em contraponto a região periférica não dispõe do mesmo capital, porém ali prevalece o pentecostalismo que historicamente se desenvolveu no meio popular e nas classes mais pobres. $\mathrm{O}$ artigo baseia-se em um mapeamento realizado no município em 2020 buscando uma configuração espacial da distribuição dos templos religiosos no município.

Palavras-chave: Religião; Centro; Periferia; Política; Santo Antônio da Platina.

\begin{abstract}
This article seeks to understand how the religious scenario is configured in the municipality of Santo Antônio da Platina-PR. This case study is based on the perception that different religious movements are developing in the central region and on the periphery of the municipality, so the main objective of this work is to differentiate them. The central region, as a social and historical construction, concentrates not only people but also a symbolic capital important for the temples that are located there, in addition to establishing a close relationship with the public administration. In contrast, the peripheral region does not have the same capital, but there Pentecostalism prevails that historically developed in the popular environment and in the poorer classes. The article is based on a mapping carried out in the municipality in 2020 seeking a spatial configuration of the distribution of religious temples in the municipality.
\end{abstract}

Keywords: Religion; Center; Periphery; Politics; Santo Antônio da Platina.

\section{Introdução}

Refletir sobre o papel desempenhado pela religião no Brasil do século XXI bem como a sua permeabilidade nas mais diversas formas de influência na sociedade, do ambiente privado ao espaço público, tornou-se extremamente importante para as mais diversas áreas do saber

\footnotetext{
1 Professor Adjunto do Centro de Ciências Humanas e Educação da Universidade Estadual do Norte do Paraná .E-mail : alfredo@uenp.edu.br

2 Graduado em História, Especialista em Ciências da Religião e Ensino Religioso e Membro do grupo de pesquisa de Ciências da Religião e Ensino Religioso na Universidade Estadual do Norte do Paraná. E-mail: wesleydossantos100@gmail.com
} 
científico, em especial para as ciências humanas e sociais.

Considerando a importância de estudar o fenômeno religioso contemporâneo e sua relação com as ações humanas, este artigo busca analisar a maneira como diferentes grupos religiosos ocupam o espaço geográfico no município de Santo Antônio da Platina-PR, apontando as diferenças existentes entre os grupos que ocupam a região central do município e os que estão presentes nas regiões periféricas.

Para analisar as diferentes ocupações destes grupos foi realizado um mapeamento dos templos religiosos presentes no perímetro urbano do município, excluindo o bairro da Platina, e os demais povoados e distritos pertencentes ao município, os quais por razão da dificuldade no acesso não puderam ser mapeados. Também foram considerados fatores históricos referentes à formação do município e fatores políticos que envolvem os interesses de diferentes grupos, para analisar a forma como se organiza o espaço destinado às práticas religiosas.

\section{Metodologia}

O município de Santo Antônio da Platina, situado ao norte do estado do Paraná, segundo dados do IBGE conta atualmente (2020) com uma população estimada em 46.251 pessoas dentre as quais, segundo o censo de 2010 mais de 30 mil pessoas se auto declararam como católicos, e mais de 9 mil como evangélicos.

Para analisar como estes grupos estão distribuídos espacialmente pelo município foi realizado um mapeamento dos templos religiosos, excluídos por motivos de acesso o bairro da Platina e demais localidades que ficam fora do perímetro urbano do município. Durante a realização do mapeamento dos templos foi utilizada a ferramenta de mapeamento digital Google Maps ${ }^{3}$ conectado a um smartphone com GPS. Utilizando desses recursos, com o deslocamento físico até cada templo era então inserido um marcador com sua localização para a elaboração de um mapa virtual com os marcadores de cada templo do município. Uma foto do local também era capturada para que fossem registrados os aspectos externos dos templos, bem como aspectos estéticos de cada um. Após a realização desses procedimentos, os marcadores e as fotos registradas compuseram uma base de dados para que as informações coletadas fossem organizadas de maneira a possibilitar a criação de um mapa virtual com as

\footnotetext{
${ }^{3}$ Após consultas em diversos sites e fontes, optou-se por utilizar esta ferramenta pela sua facilidade de acesso e compartilhamento das informações coletadas ao longo da pesquisa e pela gratuidade do serviço. A ferramenta virtual pode ser utilizada por qualquer usuário cadastrado em uma conta do Google. Ela permite que os usuários criem mapas personalizados com marcadores, rotas, linhas, imagens e textos e compartilhem essas informações de maneira livre para qualquer usuário ou de modo restrito o qual pode ser acessado somente com a autorização do autor.
} 
informações correspondentes de cada templo. ${ }^{4}$

Imagem - Mapeamento dos templos e igrejas em Santo Antônio da Platina realizado entre março/maio de 2020

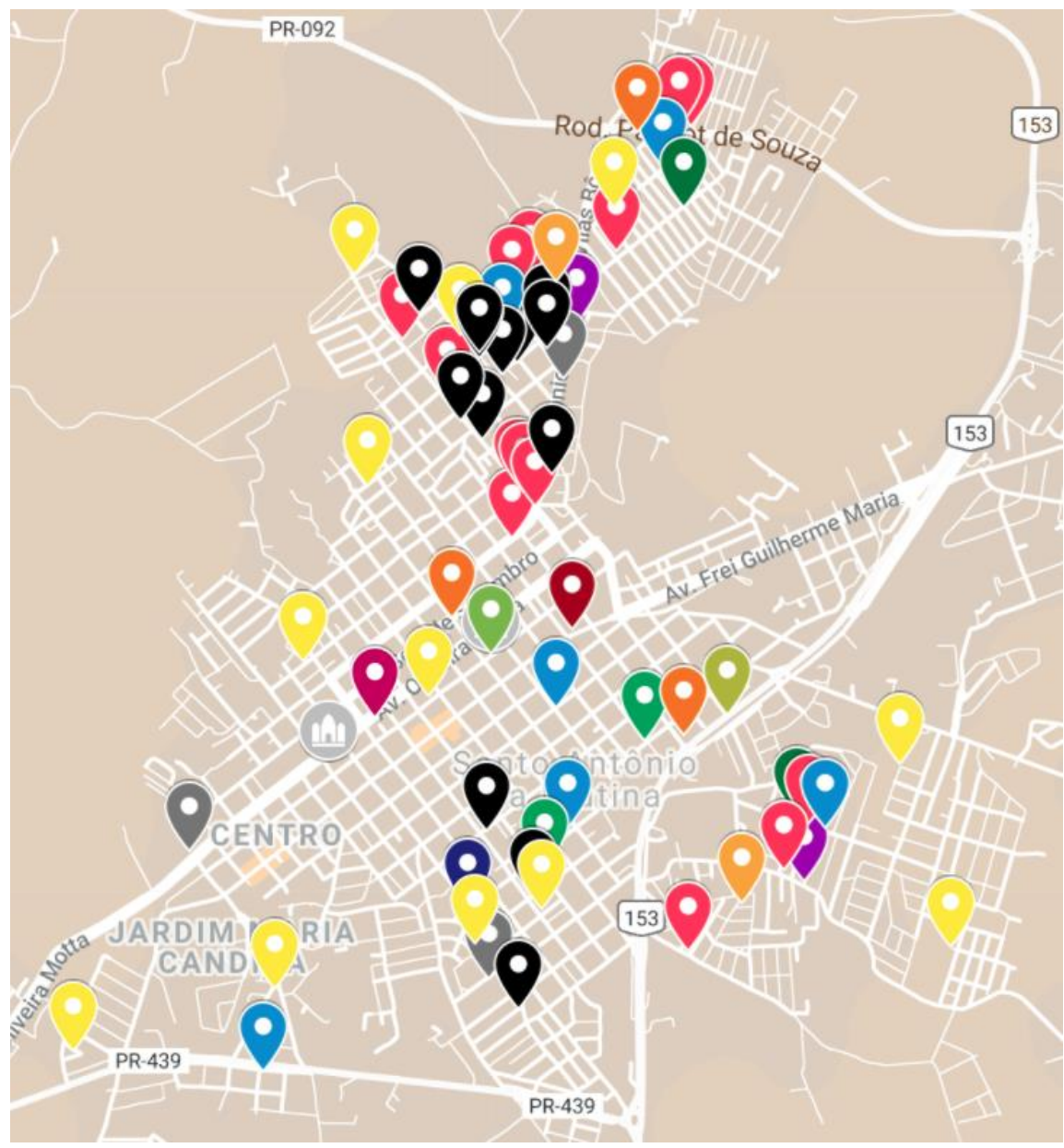

Fonte: Google Maps

O ponto central deste estudo de caso está em analisar as diferenças existentes entre os grupos cristãos que ocupam a região central do município, observando suas características próprias dos templos e dos grupos que congregam nesses locais. Por seguinte criar então uma relação com os grupos que ocupam o espaço periférico buscando analisar algumas características desses grupos. Dentre os resultados coletados durante o mapeamento foi a presença no município de aproximadamente 68 locais de culto religioso onde um deles, localizado no bairro Vila Ribeiro, uma capela católica estaria desativada, esta informação foi obtida pelos moradores do bairro após questionamentos sobre a aparência deteriorada do local.

\footnotetext{
${ }^{4}$ ARAUJO, Wesley S. Templos e igrejas em Santo Antônio da Platina entre março e maio de 2020. Google Maps: $\quad$ Google, $2020 . \quad$ Disponível em: https://www.google.com/maps/d/edit?mid=1Y4jE9gbsuCymBXEpSZ5BtDM9rsvMWDC7\&usp=sharing. Acesso em: 7 out. 2021.
} 
Outra fonte de dados consultada foi o Portal Transparência do município, onde foram observadas as leis municipais que mencionaram organizações e grupos religiosos, ou que de alguma maneira se relacionassem com o contexto religioso local. Dessa coleta foram localizadas cerca de 37 publicações entre leis e editais que se relacionavam com o tema proposto. Esses documentos serviram de base para construir uma relação entre as instituições religiosas e a administração pública local.

Como meio de compreender como ocorrem as transformações do campo religioso brasileiro nas últimas décadas foram consultados artigos, teses e trabalhos acadêmicos na área, livros e notícias a respeito, sobretudo as vinculadas em sites.

\section{Desenvolvimento}

Ao refletirmos sobre o passado de diferentes lugares podemos perceber uma forte presença das práticas religiosas em todas as civilizações. Diferentes povos, em diferentes lugares e momentos no tempo cultuavam divindades as quais eram consideradas sagradas. A presença da religião era marcante exercendo forte influência na produção cultural, na política, na economia e em todas as áreas da vida humana ao qual o indivíduo buscava no sagrado uma possível forma de orientação ou intervenção. Através de sua influência diversas nações foram criadas ou destruídas, territórios foram conquistados e fronteiras foram demarcadas ou contestadas. Por inúmeros séculos a principal instituição do mundo ocidental foi a Igreja Católica.

O século XIX foi marcado pela Revolução Industrial, pelo surgimento e consolidação de algumas ciências como a História e a Sociologia, o que gerou novos estudos sobre o papel desempenhado pelas religiões, em especial o cristianismo, principalmente nas sociedades do continente europeu. Ao longo do século XX a temática da religião foi amplamente questionada devido aos avanços do campo científico racional, principalmente em países europeus como a Alemanha, a França e a Inglaterra. O sociólogo alemão Max Weber, aponta que a "racionalização do mundo" através dos saberes científicos contrapõem a religião que constantemente desvaloriza o mundo secularizado:

A tensão entre religião e conhecimento intelectual foi comprovada de modo acentuado cada vez mais que o conhecimento empírico racional colaborou firmemente no desencantamento do mundo e sua transformação em um mecanismo causal. A ciência, então, contradiz o postulado ético de que o mundo é um cosmos ordenado por Deus e que, portanto, está significativa e eticamente guiado a alguma direção (WEBER, 2015, p. 77-78).

Os intensos debates em torno das ideias defendidas por Weber nortearam boa parte das REVISTA RELEGENS THRÉSKEIA - 2021 - UFPR 
pesquisas no campo da Sociologia das Religiões ao longo do século XX, porém a realidade vivenciada em países latino americanos como o Brasil, não condizia com a realidade que era observada na Europa do século XX. As teorias desenvolvidas em torno das ideias de Weber, bem como de outros pesquisadores em torno da secularização das sociedades consideradas modernas e da perda de espaço das religiões no mundo contemporâneo no ordenamento da vida dos indivíduos, são extremamente importantes para definir os eventos que ocorriam em parte do continente europeu, porém tornaram-se pouco representativos para a realidade brasileira. Por sua vez, o Brasil, desde a colonização portuguesa, recebe grande influência do catolicismo, e mesmo antes disso, com as práticas religiosas dos povos indígenas. Sobre esta argumentação a respeito das diferentes formas com que os movimentos religiosos se desenvolveram fora do continente europeu, Martin aponta:

caráter etnocêntrico, que tende a identificar a rota do fenômeno religioso ocorrido na Europa ocidental como caminho paradigmático pelo qual deverão transitar as outras sociedades, omitindo experiências históricas em que a religião teve grande vitalidade, como no caso dos Estados Unidos, da América Latina e da Âsia (MARTIN, 1991, p. 466 apud ZEPEDA, 2010, p.132).

Destarte a sociedade brasileira desenvolveu diferentes relações com as instituiçõos religiosas presentes no país. Mesmo após a laicização do Estado com a proclamação da República e a busca pela modernização da sociedade, inspirada pelos padrões europeus, as instituições governamentais cultivaram fortes relações com a Igreja Católica e mesmo com outros grupos religiosos. Quando nos referimos a laicidade adotada pelo estado brasileiro com o início da república no Brasil temos por pressuposto uma separação entre as esferas política e religiosa, essa separação deriva da própria secularização dos Estados republicanos contemporâneos, porém observamos que a realidade vivenciada no Brasil foi diferente do modelo adotado por outros países. Sobre essa forma de laicidade adotada no Brasil pós proclamação da República Aquino aponta:

o caráter de sua laicidade expressa na Constituição de 1891 não foi antirreligioso, ou confessional, não se assemelhou à laicidade francesa ou estadunidense. Pode-se nomeá-la de laicidade pragmática uma vez que o Estado brasileiro, ao garantir sua própria independência civil ante o 'eclesiástico, criou com o decreto 119-A um amplo espaço relacional com as confissões religiosas que oportunizava alianças, omissões, negociações, perseguições segundo os interesses próprios do Estado, ou melhor, daqueles que o controlavam. Essa laicidade foi pragmática no duplo e ambíguo sentido dessa palavra à época: correspondia ao que era útil e interessante ao Estado republicano, e, era praticada respeitando certas normas e cerimônias de corte da Igreja e do Estado. Nada mais apropriado para uma República dos Conselheiros que articulou e colocou em tensão princípios regalistas do 
Estado republicano e pressupostos institucionais juridicamente modernos de "sociedade perfeita" da Igreja Católica (AQUINO, 2012, p.77).

Assim podemos perceber que não se constituiu um Estado brasileiro completamente desprendido dos costumes religiosos que vigoravam até então, ao contrário, viria a prevalecer os interesses próprios das elites políticas em meio às circunstâncias que viriam a surgir. Tratase de uma laicidade, como aponta Aquino, de caráter pragmático e também flexível às necessidades da esfera política, onde a prática religiosa e política não viriam a se separar aos moldes de outras repúblicas como a francesa, a qual experimenta uma separação com limites claros e bem definidos entre as duas esferas. Nesse sentido, a instauração da República no Brasil não significou a instauração de um poder secularizante da sociedade, como temiam muitas lideranças católicas, ao contrário, além de cumprir os interesses políticos aos quais serviram, também tornou-se em benefício para a própria instituição católica mesmo que inicialmente a igreja se visse prejudicada. A igreja, ao ser separada do Estado, apesar de se encontrar debilitada administrativamente, pode adquirir sua independência institucional permitindo assim uma reaproximação com o Vaticano e uma reformulação da própria estrutura eclesiástica. Tal movimento culminaria no processo chamado de "diocesanização" Aquino (2012) o qual levou a expansão do catolicismo no Brasil, abrindo assim espaço para que penetrasse e expandisse suas fronteiras onde outrora o vínculo com a coroa não o possibilitava.

Assim como argumenta Monteiro (2013), a questão da secularização da sociedade brasileira adquire contornos diferentes. Considerando a questão da presença histórica no Brasil no meio político da Igreja Católica e mais recentemente de outros movimentos religiosos com destaque para os grupos neopentecostais, percebemos as questões que envolvem a participação das instituições religiosas na esfera política foram se consolidando ao longo dos últimos séculos tornando-se cada vez mais comuns. Com contornos mal definidos, a laicidade presente no país constituiu-se ao longo das décadas de maneira a permitir a presença de grupos religiosos no meio político e das instituições que governam o país. Essa presença ainda é pouco questionada, seja por falta de interesse da elite intelectual, ou mesmo por conveniência da classe política nacional. Sobre a laicidade existente no Brasil, Monteiro diz:

o regime de laicidade foi direcionado para a regulação dos direitos e deveres da Igreja católica enquanto instituição e não para erradicar a fé ou dirimir conflitos religiosos que, na verdade, até então eram percebidos como inexistentes; diante dos desafios antepostos pela heterogeneidade populacional na construção do cimento imaginário da nação prevaleceu uma ideologia assimilacionista, seja do ponto de vista racial seja do ponto de vista cultural, que fundada no ideal do sincretismo unificava as diferenças 
percebidas a partir de códigos retirados do universo teológico cristão. (MONTEIRO, 2013, p. 23).

Assim como a autora afirma, a forte presença das instituições religiosas nas diversas esferas da sociedade pode ser entendida por muitos como algo natural, sendo assim um elemento cultural da própria sociedade. Para além dos conflitos que poderiam resultar entre a interferência, ou influência, de instituições religiosas no meio político, onde o produto são leis que garantem a livre expressão religiosa, em qualquer que seja a circunstância, como dos valores democráticos da liberdade de expressão e de culto, assumidos na instauração da república. Sendo assim, a laicidade presente no Brasil, vivenciada no meio político e institucional não se limitou em separar Religião e Estado, mas pelo contrário, os uniu, os legitimou e os defende diante do argumento de assim defender a democracia e os interesses públicos.

Nas últimas décadas surgiram no país novos atores para integrar o meio político, a chamada bancada evangélica vem ganhando destaque por ser um grupo com bases eleitorais fortes no meio religioso evangélico e que vem se expandindo de maneira acentuada nos últimos

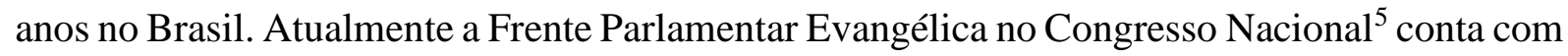
195 participantes (dados de 2019), apontam para um constante crescimento ao longo das últimas décadas. As pautas defendidas por estes parlamentares são frequentemente associadas às questões comumente chamadas de "pautas de costumes" as quais colidem diretamente com outros setores da sociedade, em especial nos casos referentes a legalização do abordo de gestação, ampliação dos direitos das comunidades LGBTQIA+, e de outras pautas que violam ou conflituam com os valores defendidos por esse grupo. A ampliação da bancada evangélica em parte se explica pelo grande crescimento das comunidades evangélicas na sociedade, o que consequentemente causa uma diminuição do espaço da Igreja Católica. Desta forma a população que se declarava evangélica em 2000 era de 26.184.941, segundo dados do IBGE, porém essa população em 2010 saltou para 42.275.440. Com esse avanço do número de evangélicos no Brasil, uma forte descrença na política brasileira a qual frequentemente é retratada na mídia envolvida em grandes esquemas de corrupção. O eleitorado evangélico busca cada vez mais sua própria representação no meio político como sendo a alternativa necessária

\footnotetext{
5 Frente Parlamentar Evangélica do Congresso Nacional: Disponível em: https://www.camara.leg.br/internet/deputado/frenteDetalhe.asp?id=54010 Acesso em: 15 mar. 2021.
} 
para que haja mudanças consistentes na política nacional que possam satisfazer os anseios políticos e visões de mundo.

\section{Diferentes espaços para adorar}

A maior parte dos templos religiosos do município de Santo Antônio da Platina estão localizados na região periférica, local que concentra também a maior parte das igrejas evangélicas. Por periferia corroboramos com a definição apresentada por Ivo (2010):

as periferias se constituem como lugares híbridos e heterogêneos de um cotidiano compartilhado por sujeitos que vivem na adversidade e na busca por justiça social e por direitos sociais e direitos sobre a cidade, como o acesso à moradia, à saúde, ao transporte, à educação e ao consumo cultural, que interagem e se mesclam com a cidade normatizada, racional, "legitimada", ultrapassando velhas noções morais de culpabilidade da pobreza ou de territórios de riscos, que podem sugerir sentidos estigmatizados de criminalização da pobreza. (IVO, 2010, p. 10).

Nessa região percebesse uma grande presença de locais com infraestrutura muito simples e na maior parte das vezes bem precárias, locais onde sequer deveriam haver reuniões de grupos por não cumprirem os requisitos exigidos pelo corpo de bombeiros para obtenção da licença de funcionamento, o que coloca em risco a realização dos eventos.

Fotografia - Igreja Assembléia de Deus no bairro Vila Ribeiro

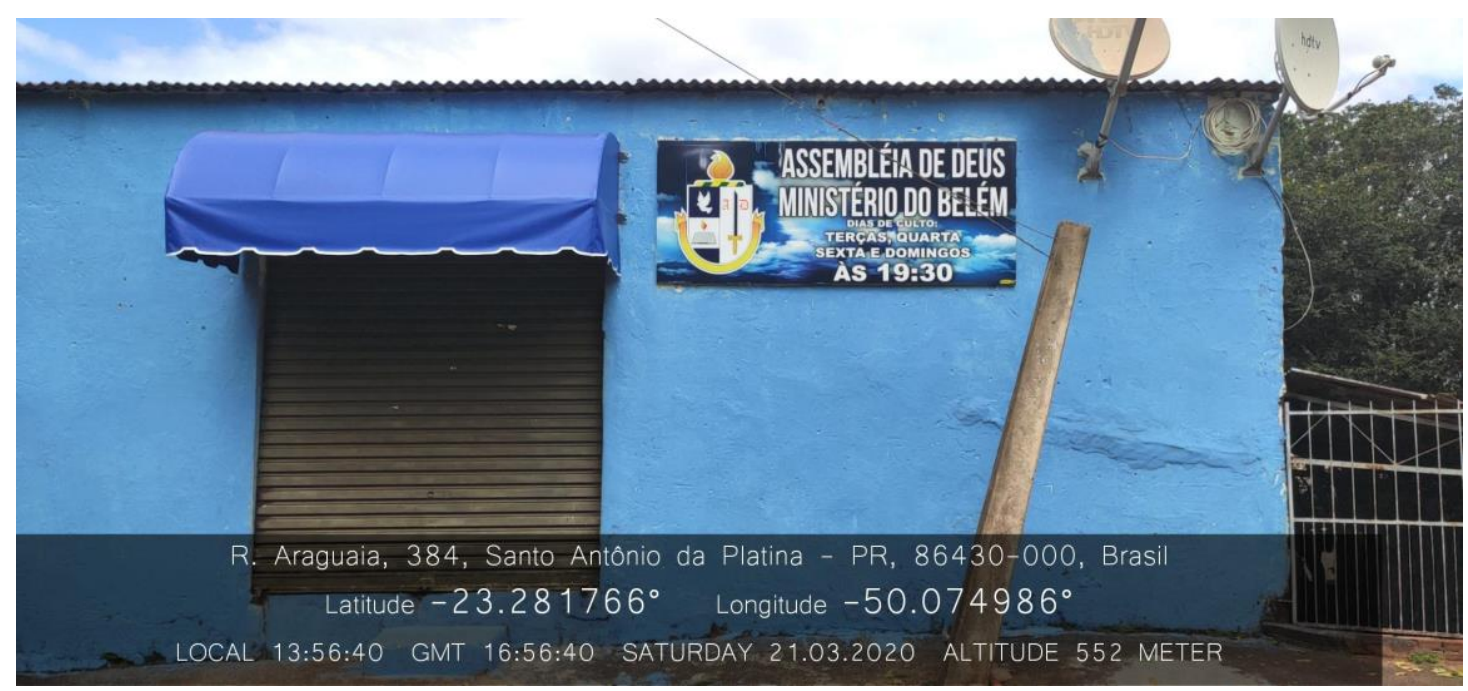

Fonte: Arquivo pessoal do pesquisador

Logo, a região central contrasta com a periférica por nela estarem além da Igreja Católica, grupos protestantes históricos como a Igreja Metodista e Presbiteriana, as neopentecostais como a Igreja Universal do Reino de Deus, Igreja Internacional da Graça de Deus e Igreja Mundial do Poder de Deus, a igreja pentecostal Congregação Cristã do Brasil, 
uma das primeiras do Brasil, o Salão do Reino das Testemunhas de Jeová e a União Espírita Jesus Nazareno. Por centro adotamos a definição de Silva:

O centro é uma área de máxima concentração de atividades econômicas dentro do tecido urbano, sendo visível na paisagem verticalizada, na densidade de estabelecimentos comerciais e de serviços, bem como no volume de pessoas transeuntes durante o horário comercial. Por outro lado, o centro é uma área marcadamente segregada do restante da cidade, identificada pela paisagem verticalizada e pela baixa densidade de ocupação residencial. (SILVA, 2013, p.2).

Com suas características distintas da região periférica, a qual concentra a população pobre, com baixos índices de escolaridade e renda, a quem das dádivas do capitalismo, a região central do município aglomera não somente prédios comerciais, nela também se localizam prédios do poder público municipal e algumas das principais denominações religiosas presentes no país atualmente as quais reverberam como as de maior impacto político e social no âmbito local. Diante disto, percebe-se que ao estar próximo da região central ou fazer estar materialmente localizado nela agregasse um valor simbólico importante para essas denominações. Logo quanto mais distante se está menor é a visibilidade e a força política dos grupos que se formam nas regiões periféricas do município.

\section{$O$ centro como espaço de disputa}

Percebemos que a organização e a ocupação territorial de templos religiosos ocorrem de maneiras diferentes no município estudado. Diante destes fatos nos resta indagar se as formas como ocorrem essas organizações são naturais ou se de alguma maneira cumprem com alguma intencionalidade pré existente para que assim ocorra?

Primeiramente entendemos que a região central do município torna-se não somente um local privilegiado no município por seus valores econômicos de terreno mais caros e aluguéis elevados pela especulação de mercado, mas também por aspectos imateriais e simbólicos. Segundo Haesbaert:

Se o espaço social aparece de maneira difusa por toda a sociedade e pode, assim, ser trabalhado de forma genérica, o território e as dinâmicas de desterritorialização (sempre hifenizada) devem ser distinguidos através dos sujeitos que efetivamente exercem poder, que de fato controlam esse(s) espaço(s) e, conseqüentemente, os processos sociais que o(s) compõe(m). Assim, o ponto crucial a ser enfatizado é aquele que se refere às relações sociais enquanto relações de poder e como todas elas são, de algum modo, numa perspectiva foucaultiana, relações de poder, este deve ser qualificado, pois, dependendo da perspectiva teórica, pode compreender desde o "antipoder" da violência até as formas mais sutis do poder simbólico (HAESBAERT, 2007, p.22). 
Segundo o autor, os processos de territorialização, ou seja, a ocupação de um território e os processos de des-territorialização, devem ser entendidos como processos de disputa de poder por diferentes atores. Para que possamos entender a forma como se constroem as relações entre centro, periferia, política e a sociedade, devemos compreender o fator simbólico que mobiliza os diferentes grupos a priorizarem sua presença na região central do município gerando conflitos em torno da ocupação dessa região. Bourdieu (1989, p.7-8) descreve como poder simbólico o "poder invisível o qual só pode ser exercido com a cumplicidade daqueles que não querem saber que lhe estão sujeitos ou mesmo que o exercem”. É necessário que se pense o espaço da cidade e tudo o que nele existe como sendo socialmente construído, portanto as relações que se desenvolvem também são formadas socialmente por diferentes grupos. Portanto o centro, como uma construção social e histórica é um local físico, com uma localização geográfica e ao mesmo tempo também um local simbólico, que aglutina diversas formas de capital. Os diferentes grupos sociais que estão incorporados nas denominações religiosas do município constroem diversas relações com a região central pela busca das variadas formas de capital que circulam nessa região. Sobre isso afirma Wacquant:

Essas construções não são efetuadas em um vácuo social, como alguns etnometodologistas parecem acreditar: a posição ocupada no espaço social — isto é, na estrutura da distribuição da diferentes espécies de capital, que são também armas - governa as representações desse espaço e as atitudes adotadas nas lutas para conservá-lo ou transformá-lo. (BOURDIEU, 1994, p.28 apud WACQUANT, 2013, p.91).

Essas relações de poder ocorrem de diferentes maneiras segundo os objetivos e propósitos estabelecidos por essas partes, onde no caso de Santo Antônio da Platina devemos entender que ocupar a região central do município inclui além de uma maior visibilidade para os moradores locais, que fluem para o centro em busca de bens e serviços, o que consequentemente gera um possível aumento de público, mas também um aumento no prestígio social dessas instituições. Devemos considerar que o público alvo dessas instituições são principalmente as pessoas dos estratos mais altos da sociedade platinense os quais possuem mais capital econômico e político. Logo, a presença das neopentecostais IURD, Internacional da Graça e Mundial as quais buscam com ímpeto fiéis da classe média e a maior proximidade possível com o público em geral, com o intuito de aumentar o número de dizimistas e ofertantes motivados pela teologia da prosperidade (MARIANO. 2014).

Outro fator que aumenta o grau de importância da região central é a proximidade que se estabelece com os prédios e locais públicos, o que cria maiores mobilizações a fim de se ter 
uma atuação política presente no município, discurso já muito conhecido no meio neopentecostal e católico mas que tem ganhado força também em outras denominações. A exemplo disto foi noticiado pelo portal de notícias NPDiário, de circulação regional, que a Igreja Metodista realizou um evento no qual 6 candidatos a prefeito do município durante as eleições municipais de 2016 discursaram durante um culto sobre suas propostas de campanha eleitoral. ${ }^{6}$ Este exemplo, mesmo que factual, revela a importância que grupos políticos vêem nas igrejas que estão nessa região, logo o centro está imbuído de uma simbologia própria que vai sendo construída socialmente de maneira a aumentar o prestígio social dos grupos que ali se estabelecem. Portanto a ocupação da região central é um fator relevante na aquisição de importância social e política bem como para o acúmulo de capital simbólico.

A estrutura do espaço social se manifesta assim, nos mais diversos contextos, sob a forma de oposições espaciais, o espaço habitado (ou apropriado) funcionando como uma espécie de metáfora espontânea do espaço social. Em uma sociedade hierarquizada, não existe espaço que não seja hierarquizado e que não exprima as hierarquias e as diferenças sociais de um modo deformado (mais ou menos) e, sobretudo, mascarado pelo efeito de naturalização acarretado pela inscrição durável das realidades sociais no mundo físico: diferenças produzidas pela lógica social podem, assim, parecer emergidas da natureza das coisas (basta pensar na ideia de "fronteira natural") (BOURDIEU, 2013, p. 134).

A própria demarcação na separação dos espaços entre centro e periferia denota um sentido opositivo entre as partes na qual a presença no centro é um fator de ostentação de poder em contraste com a imagem socialmente construída da periferia, a qual o imaginário comum remete a imagens sempre maculadas com a violência e a pobreza. Logo se estabelecem distinções entre as populações que habitam os diferentes pólos "positivos e negativos" e a cultura produzida nesses locais, os modos de viver e se apropriar dos espaços da cidade, dos postos de trabalho e dos bens e capitais simbólicos, assim vão sendo construídas as fronteiras invisíveis que marcam cada localização e os lugares sociais que cada grupo ocupa (BOURDIEU, 2013).

A paróquia Santo Antônio de Pádua, localizada em frente a praça Frei Cristóvão, na região central do município tem sua data de instalação no dia 8 de abril de 1928 e ocupa uma das regiões mais valorizadas da cidade. Atrás do templo, a poucos metros localiza-se o Fórum Municipal e o Palácio dos Dois Poderes onde são realizadas as reuniões do legislativo local. Ao longo das últimas décadas inúmeras parcerias foram estabelecidas entre o poder público e a

\footnotetext{
6 METODISTA REÚNE SEIS CANDIDATOS. Disponível em: https://www.npdiario.com.br/sub-
} capa/metodista-reune-candidatos/ Acesso em: 18 abr. 2021. 
igreja. Durante uma pesquisa realizada no Portal Transparência do município que tem seu acervo digitalizado desde $1983^{7}$, foram observadas as leis municipais número 10, 58 e 59 de 1984; 12 e 17 de 1985; 8, 23, 35, 38, 43 e 51 de 1986, tratam sobre a abertura de crédito especial adicional para a concessão de créditos para a Igreja e suas capelas situadas em outros bairros, para que fossem realizadas obras, reformas e melhorias em suas instalações. Outras leis como a número 16 de 1996 concede direitos de uso de terreno para a instalação de uma nova capela no bairro Dr Jamidas; as leis 24, 25 e 26 de 1998 que dispõe sobre a construção de uma capela e da imagem do Cristo Redentor no Morro do Bim que posteriormente se tornou um cartão postal da cidade e da abertura de crédito adicional especial no valor de $\mathrm{R} \$ 10.000,00$ para a realização da obra. Outras leis municipais tratam sobre outros casos que envolvem doações entre a prefeitura municipal e a Igreja Católica.

Apesar da maior parte das leis executadas no município referentes a grupos religiosos serem para atender a demandas católicas, outros grupos também são beneficiários dessas medidas, como exemplos temos a lei municipal número 9 de 1986 que dispõe sobre a abertura de crédito adicional especial para a Igreja Batista; a lei número 28 de 1986 que dispõe sobre a doação de terreno para a construção da sede das Testemunhas de Jeová; a lei número 42 de 1986 que trata sobre a abertura de crédito especial para a construção de um alambrado no prédio da Casa da Criança, Recanto Feliz, pertencente a Igreja Metodista; e mais recentemente o decreto 274/16 que concedeu direitos de uso à Igreja Metodista, de um galpão que se destinava ao abrigo dos trabalhadores rurais para a instalação do ponto missionário do Aparecidinho localizado no bairro Aparecidinho II. Este ponto missionário já estava implantado em um outro local no mesmo bairro, denominado Galpão da Solidariedade. Tratava-se de um local bem menor que o atual, eram apenas um pequeno salão e um banheiro. O local sofria constantemente com depredações; com a não utilização do espaço atual pela prefeitura surgiram as negociações para a utilização do barracão que custou aos cofres públicos $\mathrm{R} \$ 117.718,71$ mil reais.

Entendendo que tal região também gera conflitos entre os diferentes grupos pela presença nessa região de alto prestígio social, em 13 de março de 1997 foi emitido um decreto que prevê que a instalação de templos religiosos no município deve obedecer uma distância mínima de 150 metros de um templo para outro. Como fica demonstrado no mapa que serviu de base para o registro dos templos estabelecidos no município, esse regulamento é observado

7 Portal Transparência do município de Santo Antônio da Platina. Disponível em:<http://54.232.41.19/pronimtb/index.html> Acesso em: 7 out. 2021. 
positivamente na região central onde os templos religiosos estão devidamente distanciados entre si, porém como fica evidente esse regulamento pouco tem sido observado na parte periférica. Nessa região muitas vezes observamos templos a poucos metros de distância entre si, o que evidencia a falta de fiscalização ou mesmo de desinteresse do poder público local em fazer valer o decreto nesta região.

Os dados coletados pelo portal da transparência, o mapeamento realizado no município e a lei número 6, de 13 de março de 1997 evidenciam as disputas ocorridas entre diferentes grupos e interesses pela região central. Desta forma podemos observar como se tornam vantajosas as relações estabelecidas com o poder público e com a sociedade para as denominações que estão ali situadas. Tais grupos têm cultivado suas relações com a gestão pública a um longo período de tempo o que transformou sua presença local em um grande capital político no interior do município. Este artigo não pretende realizar apontamentos sobre a legalidade das decisões tomadas pelo poder executivo local, o objetivo é apontar as relações existentes entre o poder executivo local e diferentes denominações religiosas que atuam no município e as benesses que resultam dessas relações. No Brasil atualmente as leis que regem sobre o terceiro setor ainda são muito frágeis e pouco específicas, o que garante benefícios não apenas instituições sem fins lucrativos mas também as igrejas, não que este seja seu principal objetivo, porém não negamos que isto ocorra, o que ainda deve ser amplamente debatido sobre qual o papel das instituições religiosas no que diz respeito aos seus benefícios fiscais, pois assim como afirmam Siepierski (2001); Mariano (2003); Oro (2001) tem se estabelecido no campo religioso brasileiro denominações que operam aos moldes de grandes empresas. Parte das dificuldades encontradas para a realização das análises das fontes consultadas está nas complexas relações existentes no país entre o Estado e as instituições religiosas que participam ativamente da política nacional e local, e como o princípio da laicidade rege as interações entre as duas partes.

\section{A periferia e os neopentecostais}

A periferia compreendida neste artigo é formada pelo entorno da região central do município, que concentra a maior parte dos bairros populares. Alguns desses bairros são estigmatizados no município como zonas violentas e de altos índices de criminalidade, não surpreendentemente também são essas as regiões que concentram a maior parte dos moradores com menores índices de renda e escolaridade, além da maior parte da população negra. O que ocorre em alguns bairros é uma paisagem semelhante a de muitos lugares do Brasil, onde 
comunidades são criadas sem que recebam uma infraestrutura adequada para receber os moradores.

Apesar do seu pequeno tamanho, o município possui paisagens muito contrastantes ao caminharmos pela cidade. Enquanto existem condomínios fechados em regiões distantes do centro, cercados por muros e câmeras, também vemos localidades em que os moradores vivem em casebres feitos com madeira, lona e apenas um chão de terra batida. Diante de tais fatos fica evidente a ausência de templos religiosos nos bairros que concentram as populações de classes mais elevadas, o que restringe a presença de templos religiosos, principalmente pentecostais, as áreas em que a vulnerabilidade social é mais evidente.

Com a projeção criada pelo mapa elaborado neste artigo ficou explícito que a maior parte dos templos religiosos estão nas regiões mais periféricas do município, afastados de todo o capital simbólico existente na região central, o que converte-se em violência simbólica pela imposição da exclusão desses grupos do acesso aos bens simbólicos ali produzidos. Essa região é marcada pela presença da maioria dos grupos religiosos, sendo estes evangélicos pentecostais como a Assembleia de Deus e seus ministérios, Congregação Cristã do Brasil, Deus é Amor, Avivamento Bíblico, Evangelho Quadrangular e outros movimentos menores. Existem também capelas e paróquias da Igreja Católica e pontos missionários da Igreja Metodista distribuídos entre os bairros do município.

Trabalhos como de Rivera (2010) e Cândido (2017) possuem uma constatação semelhante a deste artigo. Neles fica evidente a concentração religiosa pentecostal na região periférica do município de São Bernardo do Campo-SP e São Gonçalo-RJ respectivamente. Estes apontamentos, mesmo que de maneira sucinta, revelam que o espaço urbano no qual o cristianismo, em sua vertente pentecostal está presente é sobretudo a periferia. Não coincidentemente trabalhos como o de Rolim (1980) já apontavam para a grande proximidade e afinidade que esse movimento possui com as classes mais pobres da sociedade brasileira. $\mathrm{O}$ teólogo e filósofo Leonildo Silveira Campos (2005), aponta em seu artigo uma das bases do pentecostalismo brasileiro como sendo o pentecostalismo norte-americano, que se desenvolve com grandes influências de outros movimentos, principalmente o movimento holiness que surge nos EUA, fruto das influências metodistas e presbiterianas. Esse movimento de massas, que atinge principalmente as populações mais pobres, negras e excluídas das benesses do capitalismo estadunidense, é de onde surgem para o também filósofo e teólogo H. Richard Niebuhr as "igrejas dos deserdados" (NIEBUHR, 1992, p.20 apud SILVEIRA, 2005, p.104) movimento que concentra o descontentamento das classes pobres com o cenário o qual 
vivenciavam. Ao adentrar o solo brasileiro na figura dos missionários Louis Francescon, que cria a Congregação Cristã no Brasil e os missionários Berg e Vingren que dão origem ao movimento Missão Fé Apostólica em Belém-PA, movimento esse que em 1918 tornou-se a Assembléia de Deus, o pentecostalismo ganha força e ao longo do último século vai se configurando como uma das maiores mudanças de paradigma do campo religioso do país.

Como já apontado anteriormente, o pentecostalismo brasileiro se desenvolve principalmente em meio a periferia e a população pobre que nela reside, por vezes longe dos direitos humanos básicos para a promoção da dignidade humana, na periferia do capitalismo e com grande desconfiança e descrença nas instituições públicas para a realização do atendimento das necessidades básicas dessas populações. O que resta a essas populações muitas vezes é a igreja ou o crime. As igrejas pentecostais, segundo Rivera (2010) podem ser consideradas locais onde ocorrem a organização social da população na periferia, espaços em que além dos cultos religiosos, há assistência aos irmãos e a integração social dos membros dessas comunidades da fé. Além disso, são nesses espaços que parte da dignidade e da autoestima dessas populações podem ser reestabelecidas. Oliveira e Rocha (2018) apontam para uma mudança de perspectivas no imaginário dessas populações consideradas marginalizadas, onde suas identidades podem passar a ser valorizadas através de uma mudança de perspectiva do imaginário já construído de pobreza e miséria. Para os autores o pentecostalismo opera reconfigurando as estruturas já estabelecidas do cristianismo católico e protestante possibilitando que as identidades marginalizadas se tornem protagonistas da própria pregação do evangelho sem a necessidade da mediação que normalmente é realizada por padres ou pastores com formação teológica. Essa reconfiguração da estrutura eclesiástica clássica ganha força no meio popular onde a baixa escolaridade é preponderante nas comunidades periféricas locais. Nessas comunidades tornase comum encontrar pequenas igrejas onde o pastor ou o pregador da palavra é um pedreiro, uma diarista ou até mesmo um cortador de cana. Postos que em comunidades tradicionalmente históricas necessitam de formação teológica mas que na periferia são ocupados por pessoas comuns.

Essa desinstitucionalização das instituições religiosas e da própria autoridade religiosa promovida pelo avanço da identidade pentecostal são pontos de estudos ainda pouco analisados no Brasil e carecem de maior atenção por aqui. Autores como Berger (2017) e Hervieu-Léger (2015) apontam para mudanças no cenário religioso contemporâneo com o surgimento de identidades religiosas mais flexíveis diante das mudanças sociais e políticas que vêm ocorrendo nos últimos anos, dos cenários de cada vez maior instabilidade econômica e incertezas sobre o 
futuro. Para Berger (2017) em seus estudos o predomínio de uma constante relativização nas relações humanas consequentemente contribui para o surgimento de um pluralismo de cosmovisões, cada vez mais intenso e irreversível. Logo, em Hervieu-Léger (2015) temos o desmonte das estruturas tradicionais que até então eram os principais atores na organização religiosa tradicional, a minoração do convertido de tipo ideal, a perda de espaço da liderança religiosa institucional promovendo assim o surgimento de novos atores no campo religioso contemporâneo.

As contribuições de ambos os autores são fundamentais para criarmos uma imagem mental do cenário platinense. A figura periférica mostra-se claramente marcada pela forte presença pentecostal, pouco institucionalizada e evidentemente voltada ao público pobre o qual se mantém afastado das estruturas do Estado, da Política e dos bens simbólicos produzidos por estes. Vemos grupos familiares e comunitários criando organizações próprias para que suas demandas imediatas por integração social possam ser atendidas e o local que isso ocorre é na igreja. Lá os seus membros além de satisfazerem suas necessidades espirituais, tem suas necessidades emocionais atendidas, seus sussurros por justiça social, por melhores condições de vida, de saúde, de prosperidade ouvidos, não somente pelo Sagrado, mas também por seus irmãos na fé que compartilham desses mesmos anseios. As relações se constroem de maneira afetivas muito intensa, e esse afeto é o fio condutor das relações também com sua liderança. Logo, na região central as relações se dão de maneira mais institucionalizada e burocrática. As relações afetivas são postas em segundo plano e em primeiro plano permanecem a hierarquia institucional. As relações políticas entre as Igrejas são evidentes, bem como a relação com o Estado que também torna-se altamente valorizada. No centro, o prestígio social das famílias tradicionais movem parte das relações que são construídas dentro do espaço institucional do templo e o poder simbólico é livremente exercitado na hierarquia do sagrado. Temos no centro uma imagem mental mais "higienizada", polida e organizada hierarquicamente criando um alto contraste com a figura que se estabelece na periferia. Nas palavras de Hervieu-Léger:

Percebe-se, assim, que os convertidos de origem popular e/ou aqueles cujo trajeto pessoal é marcado pela exclusão econômica, a marginalidade social e a privação cultural procuram majoritariamente o tipo "familiar" de agregação à linhagem crente, ao passo que a organização ético-cultural da identificação corresponde, de maneira quase exclusiva, ao caso dos convertidos de origem burguesa, que dispõem de um capital cultural e social particularmente elevado. Nesse último caso a conversão é um processo essencialmente individual, no qual a relação com a Escritura prevalece, muitas vezes, sobre a relação comunitária. (HERVIEU-LÉGER, 2015, p.119).

Tais apontamentos corroboram com os diferentes tipos de igrejas presentes no 
município, marcando a paisagem local que vai sendo moldada a partir das relações entre as instituições da administração pública e as instituições religiosas. A divisão dos espaços e dos grupos cria também um espelho da própria sociedade brasileira, com suas profundas marcas de desigualdade social e econômica, que racionalmente promove a separação entre diferentes classes sociais e que continua segregando as populações mais pobres nas regiões marginais e periféricas.

\section{Considerações finais}

Como foi anunciado até aqui, o caso de Santo Antônio da Platina possui formas organizacionais religiosas distintas entre a região central do município e a região periférica. $\mathrm{O}$ centro, como uma construção social histórica, opera como um aglutinador de capital simbólico e oportunidades de crescimento para as igrejas que nele estão estabelecidas. Logo essas instituições possuem uma forte presença na política local, operando de maneira a defender seu espaço conquistado e buscando alargar suas fronteiras. Estruturou-se uma relação com a região central que delimitou este espaço a um pequeno grupo de igrejas e de interesses. Já a periferia, operando distante da presença do Estado, constrói sua própria forma de marcar sua presença social. Os templos religiosos com predomínio do pentecostalismo familiar trazem na afetividade das relações, na sua forma mais fluida e menos burocrática de estruturar as relações entre o fiel e o Sagrado, a fórmula para atuar na periferia de maneira consistente, olhando para a realidade objetiva das pessoas que ali se fazem presentes. Tais locais não se configuram como formas antagônicas entre si, porém o contraste nas estruturas organizacionais devem ser ressaltados à medida que são construções sociais, frutos das relações humanas, ou seja, não são naturais e pré-estabelecidas apesar da sua aparente naturalidade. Também são frutos da própria sociedade externa, das formas de viver e interpretar a vida de maneira subjetiva que cada indivíduo possui.

Contudo uma das maiores dificuldades encontradas para a realização deste estudo foi a falta de fontes para demonstrar de maneira objetiva como ocorre a participação política ativa das instituições religiosas presentes no município. Portanto deixamos aqui uma lacuna aberta para novas pesquisas, que busquem apontar como ocorrem relações entre Estado e Igreja no município de maneira benéfica para ambas as partes.

\section{Referências}


AQUINO, M. Modernidade Republicana e diocesanização do catolicismo no Brasil: a construção do bispado de Botucatu no sertão paulista (1890-1923). Orientador: Ivan Esperança Rocha. 2012. 301 f. Tese (Doutorado em História) - Faculdade de Ciências e Letras de Assis Universidade Estadual Paulista, Assis - SP, 2012.

BERGER, P. L. Os múltiplos altares da modernidade: rumo a um paradigma da religião numa época pluralista. Petrópolis, RJ: Vozes, 2017.

BOURDIEU, P. Espaço físico, espaço social e espaço físico apropriado. Estudos avançados, São Paulo, v. 27, n. 79, p. 133-144, 2013. Disponível em: <http://www.scielo.br/scielo.php?script=sci_arttext\&pid=S010340142013000300010\&lng=e n\&nrm=iso>. Accesso em: 15 abr. 2021.

O poder simbólico. Rio de Janeiro: Bertrand Brasil, 2001.

CAMPOS, L. S. As origens norte-americanas do pentecostalismo brasileiro: observações sobre uma relação ainda pouco avaliada. Revista USP, [S. l.], n. 67, p. 100-115, 2005. DOI: 10.11606/issn.2316-9036.v0i67p100-115. Disponível em: <https://www.revistas.usp.br/revusp/article/view/13458>. Acesso em: 15 abr. 2021

CANDIDO, M. P. Pentecostalismo e a periferia: aspectos da relação entre a religiosidade pentecostal e o contexto de pobreza nas periferias. Orientador: Prof. Dr. CARLOS SÁVIO

TEIXEIRA. 2017. 42 f. Trabalho de Conclusão de Curso (Bacharel em Ciências Sociais) Universidade Federal Fluminense, Niterói, 2017.

HERVIEU-LÉGER, D. O Peregrino e o Convertido: A religião em movimento. 2a . ed. Petrópolis, RJ: Vozes, 2015.

IVO, A. B. L. A periferia em debate: questões teóricas e de pesquisa. Caderno CRH, Salvador, v. 23, n. 58, p. 09-15, abril 2010. Disponível em: <http://www.scielo.br/scielo.php?script=sci_arttext\&pid=S0103$49792010000100001 \& \operatorname{lng}=\mathrm{e}$ n\&nrm=iso>. Acesso em: 16 abr. 2021.

MARIANO, R. Efeitos da secularização do Estado, do pluralismo e do mercado religiosos sobre as igrejas pentecostais. Civitas - Revista de Ciências Sociais, v. 3, n. 1, p. 111-125, 3 maio, 2007.2 Disponível em: <https://revistaseletronicas.pucrs.br/ojs/index.php/civitas/article/view/112>. Acesso em: 18 abr. 2021.

Laicidade à brasileira: católicos, pentecostais e laicos em disputa na esfera pública.

Civitas - Revista de Ciências Sociais, v. 11, n. 2, p. 238-258, 16 set. 2011. Disponível em: <https://revistaseletronicas.pucrs.br/ojs/index.php/civitas/article/view/9647>. Acesso em: 18 abr. 2021.

. Neopentecostais: sociologia do novo pentecostalismo no Brasil. 5. ed. São Paulo: Edições Loyola, 2014.

MONTERO, P.; SILVA, A. L.; SALES, L. Fazer religião em público: encenações religiosas 
e influência pública. Horizonte antropológico, Porto Alegre, v. 24, n. 52, p. 131-164, 2018. Disponível em: <http://www.scielo.br/scielo.php?script=sci_arttext\&pid=S010471832018000300131\&lng=p t\&nrm=iso>. Acesso em: 16 abr. 2021.

MONTERO, P. Religião, laicidade e secularismo: um debate contemporâneo à luz do caso brasileiro. Cultura y Religión, v. II, p. 132-150, 2013.

. "Religiões Públicas" ou religiões na Esfera Pública? Para uma crítica ao conceito de campo religioso de Pierre Bourdieu. Religião e sociedade, Rio de Janeiro , v. 36, n. 1, p. 128150, junho 2016 Disponível em: <http://www.scielo.br/scielo.php?script=sci_arttext\&pid=S010085872016000100128\&lng=e n\&nrm=iso>. Acesso em: 16 abr. 2021.

OLIVEIRA, D. M.; ROCHA, A. Pentecostalismo e empoderamento de identidades marginalizadas. Pistis Praxis, Curitiba, v. 10, n. 3, p. 722-741, set/dez 2018. DOI http://dx.doi.org/10.7213/2175-1838.10.003.A004. Disponível em: <https://periodicos.pucpr.br/index.php/pistispraxis/article/view/24520>. Acesso em: 15 abr. 2021.

RIVERA, P. B. A reconfiguração religiosa contemporânea vista desde a periferia: Notas teóricas a propósito do dossiê "Religião e Periferia". PLURA: Revista de Estudos de Religião, [s. l.], v. 7, n. 1, p. 4-14, 2016. DOI: 10.18328/21790019/plura.v7n1p4-14. Disponível

em: <https://www.researchgate.net/publication/306245128_A_Reconfiguracao_Religiosa_Conte mporanea_Vista_Desde_a_Periferia_Notas_Teoricas_a_Proposito_do_Dossie_Religiao_e_ Perif eria>. Acesso em: 15 abr. 2021.

Pluralismo Religioso e Secularização: Pentecostais na periferia de São Bernardo do Campo. Rever: Revista de Estudo da Religião, [s. l.], p. 50-76, março 2010. Disponível em: <https://www.pucsp.br/rever/rv1_2010/t_rivera.pdf>. Acesso em: 15 abr. 2021.

HAESBAERT, R. Território e multiterritorialidade: um debate. GEOgraphia, v. 9, n. 17, 8 fev. 2010. Disponível em: <https://periodicos.uff.br/geographia/article/view/13531>. Acesso em: 15 abr. 2021. ROLIM, F. C. Religião e classes populares. Petrópolis, RJ: Vozes, 1980.

SIEPIERSKI, C. T. "De bem com a vida": o sagrado em um mundo em transformação: Um estudo sobre a Igreja Renascer em Cristo e a presença evangélica na sociedade brasileira contemporânea. Orientador: Profa Dra. Maria Lucia Aparecida Montes. 2001. 233 f. Tese (Doutorado em Antropologia Social) - Universidade de São Paulo, São Paulo, 2001.

SILVA, O. T.. O Conceito de Centro e Centralidade como um instrumento de compreensão da realidade urbana. XIII SIMPURB. UERJ. Rio de Janeiro, 2013.

WACQUANT, L. Poder simbólico e fabricação de grupos: como Bourdieu reformula a questão das classes. Novos estudos - CEBRAP, São Paulo , n. 96, p. 87-103, Julho 2013 . Disponível em: <http://www.scielo.br/scielo.php?script=sci_arttext\&pid=S0101$33002013000200007 \& \operatorname{lng}=\mathrm{e}$ n\&nrm=iso>. Acesso em 20 abr. 2021. 
WEBER, M. Sociologia das Religiões. Tradução: Cláudio J. A. Rodrigues. 2. ed. São Paulo: Ícone, 2015.

ZEPEDA, J. J. L. Secularização ou ressacralização? O debate sociológico contemporâneo sobre a teoria da secularização. Revista brasileira de Ciências Sociais, São Paulo, v. 25, n. 73, p. 129-141, junho 2010. 